\title{
QUALITY AND ANALYSIS OF SMALL DATA SETS - A STATISTICAL POINT OF VIEW
}

\author{
Ersbøll, $A K^{1}$, Ersbøll BK ${ }^{2}$ \\ ${ }^{1}$ The Royal Veterinary and Agricultural University, and \\ ${ }^{2}$ The Technical University of Denmark
}

We are often dealing with veterinary studies with very limited number of experimental units e.g. few animals. This might be due to complicated experiments, high cost for each animal, time demanding experiments, etc.

All other things being equal, when the data set is small, it is difficult to demonstrate significant treatment effects. It is therefore of interest to improve the quality of data in order to demonstrate significant effects. On the other hand the choice of experimental design is also very important. Furthermore, the choice of analytical methods might also have some influence on whether or not an effect can be seen.

Examples of small data sets will be given, illustrating the effect of high data quality. Different experimental designs will be discussed and the influence will be illustrated. Choosing exact methods for the statistical analysis, evaluating outliers or strange observations by influential statistics may improve the result as well.

\section{A RISK FACTOR ANALYSIS OF CHRONIC PLEURITIS IN DANISH SLAUGHTER PIG HERDS}

\author{
A. Cleveland Nielsen ${ }^{1,2 *}$, E. O. Nielsen ${ }^{3}$, A.K. Ersbøll ${ }^{1}$ \\ ${ }^{1}$ Department of Animal Science and Animal Health, The Royal Veterinary and Agricultural University, \\ Grønnegårdsvej 8, DK-1870 Frederiksberg C, Denmark \\ ${ }^{2}$ Research Centre for the Management of Animal Production and Health, Foulum, P.O. Box 50, DK-8830 \\ Tjele, Denmark, ${ }^{3}$ Danish Bacon and Meat Council, Axeltorv 3, DK-1609 Copenhagen V, Denmark
}

Respiratory disease is considered the most serious disease problem in modern pig production and the risk has increased with the intensification of the pig production (1) Respiratory disease influence the general health status and production economy of the pig herds. Chronic pleuritis (CP), as an indicator of respiratory disease, is the most common finding at the post mortem meat inspection, accounting for approximately $70 \%$ of all recordings and with an overall prevalence of $24 \%$ of all pigs slaughtered in Denmark in 1998 (2). The present study investigated and quantified risk factors for CP in Danish pig herds from the following 4 risk factor groups: herd and herd owner characteristics, management and neighbourhood factors. This combination of risk factors have not been analysed before in relation to Danish slaughter pig herds. Especially management factors are important to identify and quantify, in order to take preventive measures against respiratory disease, as they can alter the prevalence of respiratory disease in herds otherwise exposed equally $(1,3)$. In the present study, the 
occurrence of CP was investigated in 544.299 slaughter pigs from 259 farrow to finisher or finishing herds at the mandatory post mortem meat inspection on 21 abattoirs in Denmark in the period from January to August 2000, inclusive. The monthly prevalences of CP were estimated as the percentage pigs with detected CP slaughtered at a specific abattoir in a specific month. Data were obtained from databases at the Danish Bacon and Meat Council and from telephone interviews based on a questionnaire. Data were analysed using a mixed model, PROC MIXED, SAS, and taking the correlation structures due to the repeated measurements of monthly CP prevalences into account. The resulting model showed the following factors to be associated with increased prevalence of CP: low health status opposed to a herd with a high health status, pig density in a 5 kilometre radius, mingling of pigs during the production period and month of slaughter. Whereas feeding with only dry feed and practising all in all out production were protective of CP. The study demonstrated that management factors can preventively influence the prevalence of $\mathrm{CP}$ and thereby the health status of pig herds and that management factors outweighs the influence of herd size.

\title{
References
}

1. Christensen, G. and Mousing, J., 1999. Respiratory System. In: A.D. Leman, B.E. Straw, W.L. Mengeling, S. D'Allaire, and D.J. Taylor (eds.) Diseases of Swine. 8th Edition. Iowa State University Press, Ames, Iowa, 128-162.

2. Christensen, G., Enøe, C. 1999, The prevalence of pneumonia, pleuritis, pericarditis and liver spots in Danish slaughter pigs in 1998, including comparation with 1994. Dan. Veterinaertidsskr. 82, 1006 - 1015

3. Aalund, O., Willeberg, P., Mandrup, M., Riemann, H. 1976, Lung lesions at slaughter: associations to factors in the pig herd. Nordic Veterinary Medicine 28, 487 - 495

\section{A NATIONAL PLAN FOR THE CONTROL AND ERADICATION OF ENZOOTIC PNEUMONIA IN NORWEGIAN SWINE HERDS}

\author{
Bjørn Lium and Børge Baustad \\ Norwegian Pig Health Service, Oslo
}

Enzootic pneumonia caused by Mycoplasma hyopneumoniae has a worldwide distribution and causes great losses in the swine industry. Depending on environmental factors, it may cause varying degrees of a bronchopneumonia and will reduce daily weight gain. According to Norwegian and Finnish findings, enzootic pneumonia reduces daily weight gain between 40 and 60 grams per day during the growing period up until slaughter. The disease will also increase the risk for additional lung infections by other pathogens.

In a survey made in 1998, the prevalence of Norwegian swineherds seropositive for M. hyopneumoniae was found to vary between regions, from five percent up to 40 percent. All elite breeding and multiplying herds in Norway are free from the infection. Actinobacillus pleuropneumoniae is prevalent in most Norwegian swineherds. Norway is free from several of the important viral lung pathogens, such as swine influenza virus, PRCV, PRRSV and Aujeszky's Disease virus.

Eradication of enzootic pneumonia has been successful in approximately 90 percent of more than the 
100 Norwegian swineherds where eradication programmes have been performed. Most eradications have been performed using the Zimmermann method, where breeding animals older than 10 months are kept in the herd, while younger animals are removed. No farrowings take place during the eradication period. After a thorough cleaning of the premises, all remaining animals are medicated daily with tiamulin in the drinking water for a two-week period.

In 1999, a project was started to eradicate enzootic pneumonia from all swineherds in one region in southern Norway. In 2000, similar projects were started in two other regions, central Norway and northern Norway.

At the end of 2000, most of the herds in these regions have been serologically tested for antibodies against $M$. hyopneumoniae, and in most of the seropositive herds the disease has been eradicated. Only one herd was known to be positive in the region where the project started, but a few herds remained to be tested. In central and northern Norway, 27 and 4 herds were known to be positive, respectively.

In 2001, a plan was passed to test pigs in all Norwegian swineherds for antibodies against $M$. hyopneumoniae. During a five-year period, all the remaining un-tested swineherds will be tested. During that period, the disease will be eradicated in all herds in the three regions included in the initial eradication projects as well as in northwestern Norway. Throughout the rest of the country, the eradication will already be in progress.

The parties involved in the project are the slaughterhouse companies, co-operative as well as private, the swine breeders' organisation, and the official veterinary authorities. The Norwegian Pig Health Service, which is organised as cooperation between the mentioned parties along with the Norwegian Veterinary Association and the Veterinary Institute, is the coordinating the project. The slaughterhouse companies, the Norwegian Pig Health Service and the individual farmers involved, finance the plan.

\title{
REPORTED TREATMENT INCIDENCE RATE PROFILE OF MAIN PRODUCTION DISEASES OF DAIRY FARMS IN DENMARK 1992-1999
}

\author{
Lawson L. G. ${ }^{1}$, Agger J. F. ${ }^{1}$, Skjøth F. ${ }^{2}$, Nielsen L. A. H. ${ }^{2}$ \\ ${ }^{1}$ Department of Animal Science and Animal Health, The Royal Veterinary \& Agricultural University, \\ DK-1870 Frederiksberg C, Denmark. ${ }^{2}$ National Department of Cattle Husbandry, Danish Agricultural \\ Advisory Centre, DK- 8200 Århus N, Denmark.
}

Integrating disease information in genetic and production improvement for dairy cattle requires detailed registration of disease occurrence. In Denmark, this information need was the main reason for establishing the Danish Cattle Disease Database in 1989 in 3 selected geographic areas and subsequently in 1992 for the whole country. The database has been used to investigate genetic correlation between various production diseases and genetic traits. Selection indexes have been developed to help farmers select breeding stocks that are more resistant to major production diseases like mastitis. Further the database has been used in epidemiological studies to identify risk factors associated 
with production diseases. However, the use of reported treatments as indicators of disease incidence has been met with reservations. Possible reasons are that 1) reporting is influence by the farmers' ability to identify the disorder. 2) Farmers have different attitudes towards calling the veterinarian and are highly influenced by the cost of treatment. 3) Farmers as well have different risk aversion towards the impact of the disease on milk output. To get an overview of reported treatments, this paper investigated and identified reporting profiles for the main production diseases from 1992 to 1999.

\section{Data material and methods}

Data was based on a stratified representative random sample of dairy farms provided by the Danish Institute of Agriculture and Fisheries Economics for the period 1996-1999. Information on reported treatment of production diseases from 1992 to 1999 was collected from the Danish Cattle Database through the National Department of Cattle Husbandry. Regression models were formulated to investigate the level of reported treatment over time and identify reporting profiles for the main production diseases.

\section{Results}

As already known, mastitis reported treatment is the most common production disease. It is represented by cubic polynomial with a stable level of incidence rate (0.25) per cow between 1995 and 1998. Other disorders (unclassified disorders), Reproduction disorders and Milk fever incidence rate follow the same pattern like mastitis but at incidence rates between 0.03 and 0.17 per cow year (Fig. 1).

However, Lameness is represented by a linear trend with an incidence rate from 0.03 to 0.05 per cow year. For the disorders in question, incidence rates in 1999 seem to be higher than all years. It is unclear if the increase in 1999 is due to better utilization of the registration or the reporting system, or it is a real increase in disease frequencies.

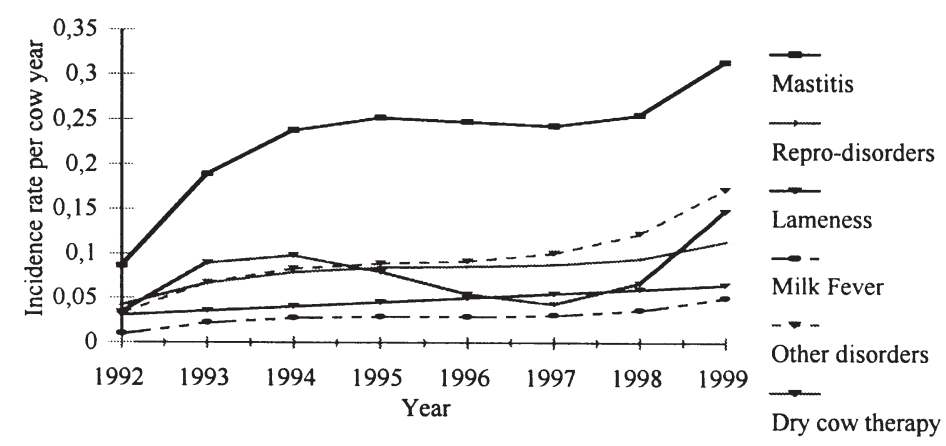

Fig. 1. Average production disease reported treatment incidence rate profile. 